\title{
A single-nucleotide polymorphism in the interleukin-1 receptor-associated protein gene is associated with impaired glucose regulation and type 2 diabetes in a case-controlled study
}

\author{
QIANG WEN $^{1 *}$, FANGQIN WU $^{1 *}$, JINHUA YANG $^{1}$, JINGJING WU $^{1}$, XIAOMIN ZHANG ${ }^{2}$, \\ MEIAN HE ${ }^{2}$, TANGCHUN WU ${ }^{2}$ and LONGXIAN CHENG ${ }^{1,3}$
}

\begin{abstract}
${ }^{1}$ Department of Cardiology, Union Hospital, Tongji Medical College, Huazhong University of Science and Technology, Wuhan, Hubei 430022; ${ }^{2}$ Education Key Laboratory of Environment and Health, School of Public Health, Tongji Medical College, Huazhong University of Science and Technology, Wuhan, Hubei 430030; ${ }^{3}$ Department of Cardiology, Liyuan Hospital, Tongji Medical College, Huazhong University of Science and Technology, Wuhan, Hubei 430077, P.R. China
\end{abstract}

Received January 30, 2015; Accepted February 20, 2015

DOI: $10.3892 /$ br.2015.453

\begin{abstract}
Impaired glucose regulation (IGR), containing prediabetes and diabetes, is an inflammatory disease. The interleukin-33 (IL-33)/IL-1 receptor-like 1 and IL-1/IL-1 receptor (IL-1R) pathways are involved and play opposite roles. While the IL-1R-associated protein (IL-1Rap) is indispensible for the two pathways, the association between the single-nucleotide polymorphisms (SNPs) of the IL-IRap gene and IGR has not been determined. TaqMan probe quantitative polymerase chain reaction was used to genotype 11 SNPs in the regions of the $I L-1$ Rap gene selected on the basis of linkage disequilibrium using the HapMap database in a study of 889 individuals (156 IGR patients in the case group and 733 non-diabetic patients in the control group). Logistic regression was applied to control the potential confounders in the multivariate analysis. Among 11 SNPs, IL-1Rap rs3773958 was associated with IGR. Further analysis showed that the odds ratios for GT and GT + GG carriers vs. TT carriers were 1.686 and 1.669, respectively, adjusted for gender, age, weight, waist, drinking, smoking, hypertension, alanine aminotransferase, total cholesterol and triglycerides. For rs3773958 in the non-smoking subgroup, GT and GT + GG carriers had a significantly higher risk of IGR compared to the TT carriers. The same conclusions were drawn using data from non-drinking and non-overweight subgroups. However, interactions between
\end{abstract}

Correspondence to: Professor Longxian Cheng, Department of Cardiology, Union Hospital, Tongji Medical College, Huazhong University of Science and Technology, 1277 Jiefang Road, Wuhan, Hubei 430022, P.R. China

E-mail: chenglongxian@sina.com

*Contributed equally

Key words: polymorphism, IL-1Rap, impaired glucose regulation, type 2 diabetes, Chinese Han population rs3773958 and smoking, drinking or being overweight were not significant. In conclusion, rs3773958 in the IL-1Rap gene region was associated with IGR.

\section{Introduction}

Diabetes has become a global health problem now and one large epidemiological study by Xu et al (1) reported that the pre valence of diabetes in Chinese adults has reached to $11.6 \%$. Therefore, novel and more effective treatment and prevention efforts are required to reduce the prevalence of diabetes and improve patients outcomes.

Studies have shown that the inflammatory state can lead to insulin resistance (2) and islet destructions, including apoptosis (3). When reduced insulin secretion fails to compensate for insulin resistance, type 2 diabetes mellitus (T2DM) develops (4). Among the pro-inflammatory cytokines, the interleukin-1 (IL-1) family is well-known and important, as shown by ample evidence from protein to gene levels (5). Certain other cytokines also play a pivotal roles: IL-6 and C-reactive protein are reported to be predictive of T2DM $(6,7)$.

IL-33 together with its orphan receptor IL-1 receptor-like 1 (mST2) forms a new anti-inflammatory pathway, as validated by protecting adipose tissue of obese mice from inflammation and thus alleviating the plasma glucose level (8). Studies showed that sST2 (a decoy receptor of mST2) was associated with diabetes in two large community-based cohorts $(9,10)$. In addition to IL-33, decreased adiponectin levels are associated with an increased risk for the incidence of T2DM (11). Thus anti-inflammatory cytokines protect against the development of T2DM.

As shown in previous studies, the IL-1 receptor-associated protein (IL-1Rap) encoded by the IL-1Rap gene, which is located on human chromosome 3q28, spanning $\sim 147.02 \mathrm{~kb}$ and containing 13 exons (http://www.ncbi.nlm.nih.gov/gene), is indispensible for the IL-1/IL-1R and IL-33/ST2 pathways $(12,13)$. While the balance between pro- and anti-inflammation is critical for the development of diabetes, attention should be focused to a protein that is essential for two opposite cytokines 
to function. Wang et al (14) identified that the IL-IRap gene is upregulated in fulminant type 1 diabetes. However, to the best of our knowledge, no investigators have studied the associations of single-nucleotide polymorphisms (SNPs) in the IL-1Rap gene region with impaired glucose regulation (IGR).

In the present study, the associations of the SNPs in the IL-1Rap gene with IGR were investigated in the Chinese Han population. The results provided important insights into the pathogenesis of IGR.

\section{Materials and methods}

Study population. The study population came from the control group of a previous study investigating the association between hsp60 SNPs and coronary heart disease (CHD); the inclusion criteria of CHD were fully described in the previous study (15). A total of 889 unrelated Han Chinese patients were selected. Of these patients, 156 (117 T2DM, 32 with impaired fasting glucose and 7 with impaired glucose tolerance) were diagnosed based on i) the diagnosis of diabetes when discharged; ii) having a diabetic history or using antihyperglycemia drugs for $>2$ weeks; and iii) having a fasting plasma glucose (FPG) between 6.1 and $7.0 \mathrm{mmol} / 1$ (inclusive) for IGR .

A questionnaire was also introduced to obtain data on patient lifestyles, medical histories and sociodemographic information. The definitions of smokers, body mass index (BMI) and hypertension were described previously (15). BMI was dichotomized according to its mean value and overweight was defined as having a BMI of $\geq 24.00 \mathrm{~kg} / \mathrm{m}^{2}$. Written informed consent was obtained from all the participants. The Ethics Committee of Tongji Medical College (Huazhong University of Science and Technology, Wuhan, China) approved the study.

Selection and sequencing of SNPs. In total, 11 SNPs were selected according to the following criteria: $\mathrm{r}^{2} \geq 0.8$ and minor allele frequency (MAF) $\geq 0.1$ using HapMap Phase I Chinese data (http://www.hapmap.org). Additionally, 2000-bp extensions were examined on the $5^{\prime}$ and $3^{\prime}$ ends of the ILIRap gene.

Genomic DNA was isolated from leukocytes with a Puregene kit (Gentra Systems, Inc., Minneapolis, MN, USA). SNPs were genotyped using TaqMan SNP allelic discrimination on an ABI 7900HT (Applied Biosystems, Foster City, CA, USA). Polymerase chain reaction (PCR) was carried out using the TaqMan Universal PCR Master mix (no AmpErase UNG) and Probe/Primer mix (Applied Biosystems) according to the manufacturer's instructions. PCR conditions included $95^{\circ} \mathrm{C}$ for $10 \mathrm{~min}$, followed by 40 cycles of $15 \mathrm{sec}$ at $92^{\circ} \mathrm{C}$ and $1 \mathrm{~min}$ at $60^{\circ} \mathrm{C}$. Two blank controls (DNA hydration solution) and two replicate quality control samples were included in each 384-well format. Two replicate samples were genotyped with $100 \%$ concordance.

Biochemical variables. FPG, total cholesterol (TC), triglyceride (TG) and alanine aminotransferase (ALT) were assayed using standard lab procedures in the Department of Clinical Laboratory of the Union Hospital (Tongji Medical College).

Statistical analysis. Continuous variables were expressed as mean \pm standard deviation and Student's t-tests were used
Table I. General characteristics of the patients enrolled.

\begin{tabular}{lccc}
\hline Characteristics & $\begin{array}{c}\text { Case } \\
(\mathrm{n}=156)\end{array}$ & $\begin{array}{c}\text { Control } \\
(\mathrm{n}=733)\end{array}$ & P-value \\
\hline Age, years & $63.2 \pm 9.3$ & $59.8 \pm 11.5$ & $<0.001^{\mathrm{a}}$ \\
Gender, m/f & $122 / 34$ & $599 / 134$ & 0.312 \\
BMI, $\mathrm{kg} / \mathrm{m}^{2}$ & $24.09 \pm 3.32$ & $23.78 \pm 3.33$ & 0.282 \\
Waist, cm & $84.6 \pm 10.2$ & $84.1 \pm 9.9$ & 0.603 \\
ALT, $\mathrm{mmol} / \mathrm{l}$ & $26.9 \pm 16.1$ & $24.5 \pm 16.2$ & 0.095 \\
TC, $\mathrm{mmol} / \mathrm{l}$ & $4.88 \pm 1.02$ & $4.67 \pm 0.90$ & $0.016^{\mathrm{a}}$ \\
TG, $\mathrm{mmol} / \mathrm{l}$ & $1.81 \pm 1.87$ & $1.62 \pm 1.14$ & 0.219 \\
FBG, $\mathrm{mmol} / \mathrm{l}$ & $8.0 \pm 3.3$ & $4.7 \pm 0.5$ & $<0.001^{\mathrm{a}}$ \\
Drinking, yes/no & $50 / 106$ & $254 / 497$ & 0.534 \\
Smoking, yes/no & $86 / 70$ & $404 / 329$ & 0.998 \\
Hypertension, yes/no & $95 / 61$ & $301 / 432$ & $<0.001^{\mathrm{a}}$
\end{tabular}

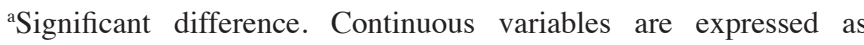
mean \pm standard deviation, and categorical variables are expressed as counts. BMI, body mass index; ALT, alanine aminotransferase; TC, total cholesterol; TG, triglycerides; FBG, fasting blood glucose; m, male; f, female.

to compare the means between groups. Categorical values were expressed as counts and tested by $\chi^{2}$ tests, which were also used to compare differences in genotype distributions of polymorphisms between case and control groups. Binary logistic regression analyses were applied to calculate odds ratios (ORs) and 95\% confidence intervals (CIs) adjusted for gender, age, overweight, waist, ALT, TC, TG, drinking, smoking and hypertension if a significant difference was identified. All the analyses were performed using SPSS 12.0 (SPSS Inc., Chicago, IL, USA). Haploview 4.2 (http://www. broad.mit.edu/mpg/haploview/) was used to analyze MAF, Hardy-Weinberg equilibrium (HWE) and heterozygosity. PASS 12.0 was used to calculate the test power (http://www. ncss.com/). The study had $84.5 \%$ power to detect the associations of rs3773958 with IGR, provided the true OR was 1.686 , at a significance level of 0.05 (two-sided). $\mathrm{P}<0.05$ was considered to indicate a statistically significant difference.

\section{Results}

General characteristics of the patients enrolled. In the present study, patients in the case group were more likely to have hypertension than those in the control group $(\mathrm{P}<0.001)$ and case group patients had significantly higher levels of TC $(4.88 \pm 1.02 \mathrm{mmol} / 1$ vs. $4.67 \pm 0.90 \mathrm{mmol} / 1$, respectively; $\mathrm{P}=0.016)$ and FPG $(8.0 \pm 3.3 \mathrm{mmol} / 1 \mathrm{vs} .4 .7 \pm 0.5 \mathrm{mmol} / \mathrm{l}$, respectively; $\mathrm{P}<0.001)$, as well as increased age (63.2 \pm 9.3 years vs. $59.8 \pm 11.5$ years, respectively; $\mathrm{P}<0.001)$. No significant differences were identified for gender, BMI, waist measurement, ALT, TG, drinking and smoking between the two groups (Table I).

Linkage disequilibrium of the IL-1Rap gene SNPs. A total of 11 SNPs were sequenced for the IL-IRap gene. MAFs ranged 
Table II. Distribution of 11 SNPs in the IL-1Rap gene region by sequencing.

\begin{tabular}{|c|c|c|c|c|c|c|c|}
\hline rs ID & Chr. Pos. & MAF & HWE & Alleles & Function & Het & P-value \\
\hline rs9817203 & 191711042 & 0.321 & 0.8707 & $\mathrm{C}: \mathrm{T}$ & IL-1Rap & 0.440 & 0.702 \\
\hline rs16865597 & 191758239 & 0.110 & 0.9890 & $\mathrm{~T}: \mathrm{C}$ & IL-1Rap & 0.198 & 0.578 \\
\hline rs3773986 & 191761609 & 0.126 & 0.1547 & $\mathrm{C}: \mathrm{T}$ & IL-1Rap & 0.232 & 0.783 \\
\hline rs3773981 & 191762859 & 0.195 & 1.0000 & $A: C$ & IL-1Rap & 0.314 & 0.301 \\
\hline rs4687150 & 191763578 & 0.299 & 0.4501 & $\mathrm{C}: \mathrm{T}$ & IL-1Rap & 0.407 & 0.727 \\
\hline rs1559018 & 191779777 & 0.489 & 0.2694 & $\mathrm{~A}: \mathrm{G}$ & IL-1Rap & 0.520 & 0.252 \\
\hline rs6444435 & 191786499 & 0.208 & 0.1725 & $\mathrm{G}: \mathrm{A}$ & IL-1Rap & 0.313 & 0.783 \\
\hline rs3773958 & 191792297 & 0.430 & 0.5793 & $\mathrm{~T}: \mathrm{G}$ & IL-1Rap & 0.480 & $0.066^{\mathrm{a}}$ \\
\hline rs6765375 & 191810446 & 0.201 & 0.1869 & $\mathrm{~A}: \mathrm{C}$ & IL-1Rap & 0.336 & 0.832 \\
\hline rs1015704 & 191821106 & 0.039 & $2.4253 \mathrm{E}-64^{\mathrm{a}}$ & $\mathrm{A}: \mathrm{G}$ & IL-1Rap & $<0.001$ & 0.195 \\
\hline rs4624606 & 191836940 & 0.180 & 0.1517 & $\mathrm{~T}: \mathrm{A}$ & IL-1Rap & 0.310 & 0.267 \\
\hline
\end{tabular}

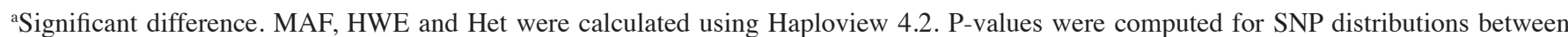
case and control groups using the $\chi^{2}$ test. MAF, minor allele frequency; HWE, Hardy-Weinberg equilibrium; Het, heterozygosity; SNPs, single-nucleotide polymorphisms; IL-1Rap, interleukin-1 receptor-associated protein; ID, identity; Chr. Pos., chromosome position.

Table III. Association between rs3773958 and IGR.

Genotype Case, n (\%) Control, n (\%) Crude OR (95\% CI) Crude P-value Adjusted OR (95\% CI) Adjusted P-value

\begin{tabular}{lrlllll}
\hline$T T$ & $39(25.0)$ & $254(34.7)$ & 1 & & 1 & \\
$G T$ & $84(53.8)$ & $343(46.8)$ & $1.595(1.055-2.411)^{\mathrm{a}}$ & $0.026^{\mathrm{a}}$ & $1.686(1.101-2.582)^{\mathrm{a}}$ & $0.016^{\mathrm{a}}$ \\
$G G$ & $33(21.2)$ & $136(18.6)$ & $1.580(0.951-2.627)$ & 0.078 & $1.627(0.965-2.745)$ & 0.068 \\
$G G+G T$ & $117(75.0)$ & $479(65.3)$ & $1.591(1.074-2.357)^{\mathrm{a}}$ & $0.020^{\mathrm{a}}$ & $1.669(1.114-2.501)^{\mathrm{a}}$ & $0.013^{\mathrm{a}}$ \\
\hline
\end{tabular}

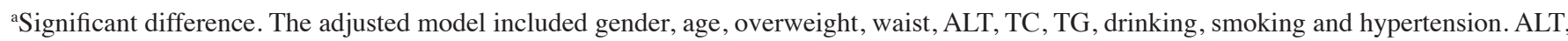
alanine aminotransferase; TC, total cholesterol; TG, triglycerides; OR, odds ratio; CI, confidence interval; IGR, impaired glucose regulation.

from 0.039 to 0.489 and rs1015704 was deviated from the HWE using Haploview 4.2 (Table II).

Analysis of the associations between the IL-1Rap SNPS and $I G R$. The analysis revealed that rs3773958, an SNP in the IL-1Rap gene, was likely associated with IGR $(\mathrm{P}=0.066)$, while the others were not (Table II). Additionally, a significant association was demonstrated for rs3773958, with crude ORs for GT and GT + GG vs. TT of 1.595 (CI, 1.055-2.411; P=0.026) and $1.591(\mathrm{CI}, 1.074-2.357 ; \mathrm{P}=0.020)$ and adjusted $\mathrm{ORs}$ of 1.686 (CI, 1.101-2.582; $\mathrm{P}=0.016)$ and 1.669 (CI, 1.114-2.501; $\mathrm{P}=0.013$ ), respectively, following adjustment for gender, age, overweight, waist measurement, ALT, TC, TG, drinking, smoking and hypertension (Table III).

Stratification of rs3773958 and IGR in subgroups of the enrolled patient population. As shown in Table IV, non-smokers, non-drinkers and non-overweight individuals with genotypes GT and GT + GG showed a significant difference in gene distributions compared to those with the genotype TT, with adjusted ORs of 2.136 (CI, 1.213-3.764; P=0.009), 2.019 (CI, 1.175-3.469; $\mathrm{P}=0.011), 2.177 \quad(\mathrm{CI}, 1.275-3.720 ; \mathrm{P}=0.004)$, 2.119 (CI, 1.273-3.524; $\mathrm{P}=0.004), 2.224$ (CI, 1.224-4.043; $\mathrm{P}=0.009)$ and $2.008(\mathrm{CI}, 1.136-3.550 ; \mathrm{P}=0.017)$, respectively.
However, no interaction was identified between rs3773958 and smoking, drinking or being overweight (Table V).

\section{Discussion}

In the present study, rs3773958, located in a IL-1Rap gene, was associated with IGR in the Chinese Han population. To the best of our knowledge, this is the first time that the SNPs of the IL-1Rap gene have been investigated in the context of associations with IGR and these data provide important insights into the role of IL-1Rap in the pathogenesis of IGR.

IL-33, discovered in 2005 and widely expressed in fibroblasts, epithelial cells and endothelial cells (16), is reported to exert cardioprotective effects $(17,18)$. In fat tissues, IL-33 and ST2 present a paracrine and positive-feedback signaling mechanism $(19,20)$. Further study shows that the IL-33/ST2 pathway enhances the secretion of T-helper 2 (Th2) cytokines of adipocytes, promotes accumulation of Th2 cells in fat tissues and transforms macrophages into a protective M2 type, all presenting anti-inflammation effects, concomitant with reducing fasting blood glucose and improving insulin resistance (8). In addition, together with T-regulatory cells, the pathway may exert its protective role by inhibiting the Th1/Th17 cell reaction in islets $(21,22)$. For the IL-1 family, 
Table IV. Stratification study between rs3773958 and IGR.

\begin{tabular}{|c|c|c|c|c|c|c|c|}
\hline \multirow[b]{2}{*}{ Characteristics } & \multirow{2}{*}{$\frac{\mathrm{TT}}{\text { Ref. }}$} & \multicolumn{2}{|l|}{ GG } & \multicolumn{2}{|l|}{ GT } & \multicolumn{2}{|l|}{$\mathrm{GG}+\mathrm{GT}$} \\
\hline & & OR $(95 \%$ CI $)$ & P-value & OR $(95 \% \mathrm{CI})$ & P-value & OR $(95 \% \mathrm{CI})$ & P-value \\
\hline Smoking & 1.000 & $1.500(0.678-3.314)$ & 0.317 & $1.170(0.595-2.297)$ & 0.649 & $1.266(0.675-2.377)$ & 0.463 \\
\hline Non-smoking & 1.000 & $1.739(0.855-3.539)$ & 0.127 & $2.136(1.213-3.764)$ & $0.009^{\mathrm{a}}$ & $2.019(1.175-3.469)$ & $0.011^{\mathrm{a}}$ \\
\hline Drinking & 1.000 & $1.031(0.399-2.665)$ & 0.950 & $1.016(0.489-2.112)$ & 0.965 & $1.020(0.509-2.044)$ & 0.955 \\
\hline Non-drinking & 1.000 & $1.989(1.046-3.780)$ & 0.036 & $2.177(1.275-3.720)$ & $0.004^{\mathrm{a}}$ & $2.119(1.273-3.524)$ & $0.004^{\mathrm{a}}$ \\
\hline Overweight & 1.000 & 1.617 (0.776-3.370) & 0.200 & $1.398(0.744-2.626)$ & 0.298 & $1.467(0.812-2.648)$ & 0.204 \\
\hline Non-overweight & 1.000 & $1.531(0.710-3.299)$ & 0.277 & $2.224(1.224-4.043)$ & $0.009^{\mathrm{a}}$ & $2.008(1.136-3.550)$ & $0.017^{\mathrm{a}}$ \\
\hline
\end{tabular}

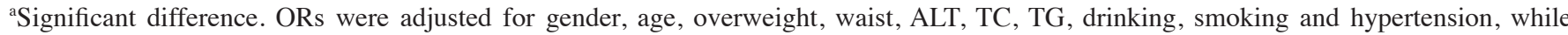
smoking, drinking, overweight were absent in the model when stratified according to each parameter. ALT, alanine aminotransferase; TC, total cholesterol; TG, triglycerides; ORs, odds ratios; CI, confidence interval; IGR, impaired glucose regulation; Ref, reference.

Table V. Interaction between rs3773958 and drinking, smoking and being overweight.

\begin{tabular}{lcc}
\hline rs3773958 interaction & OR $(95 \%$ CI $)$ & P-value \\
\hline Drinking & $0.683(0.441-1.058)$ & 0.087 \\
Smoking & $0.893(0.589-1.353)$ & 0.594 \\
Overweight & $0.766(0.505-1.162)$ & 0.209 \\
\hline
\end{tabular}

ORs and P-values for interactions were calculated with gender, age, overweight, waist, ALT, TC, TG, drinking, smoking, and hypertension adjusted using logistic regression analysis by the multiplication principle. ALT, alanine aminotransferase; TC, total cholesterol; TG, triglycerides; OR, odds ratio; CI, confidence interval.

in vitro study has shown that treating islet cells with IL-1 receptor antagonist (IL-1Ra), a natural competitor of IL-1- $\beta$, leads to decreased secretion of IL-6 and other inflammatory cytokines, as observed in the islet cells of IL-1- $\beta$ knockout mice compared to wild-type mice. Treatment with IL-1Ra in vivo can decrease blood sugar concentration and the degree of inflammatory cell infiltration into the Langerhans' islets (23). Additionally, the plasma IL-1- $\beta$ level is elevated in overweight/obese prediabetes compared to overweight/obese healthy controls, although without a significant difference, the glycated hemoglobin $\mathrm{A} 1 \mathrm{c}\left(\mathrm{HbA}_{\mathrm{lc}}\right)$ is positively correlated with IL-1- $\beta$ (24).

IL-1Rap is essential for IL-33/ST2 signaling (25), required for IL-1- $\beta /$ IL-1R signaling (13) and may represent a common $\beta$-strand shared by IL-1R1, IL-1R2, IL-1Rrp2 and IL-33Ra (12). Another form of IL-1Rap also exists, which is soluble IL-1Rap (sIL-1Rap) produced by alternative splicing, and is reported to assist $\mathrm{sST} 2$ in blocking the effectiveness of the IL-33/ST2 pathway (25) and antagonize the role of IL-1 (26,27). From the 11 SNPs sequenced in the present study, a significant difference was identified for only one SNP, rs3773958, with OR 1.686 for GT and 1.669 for GT + GG following adjustment, which means increased susceptibility to IGR. Although the clear mechanisms remain to be further explored, the possible reason may lie in that i) the absolute expression of IL-1Rap and associated proteins differ in tissues, particularly the pancreas and adipose tissue; ii) the affinities of the IL-1- $\beta /$ IL-1R complex and IL-33/ST2 complex for IL-1Rap, determining which pathway exerts the larger momentum to affect disease progression; and iii) the unknown impact on sIL-1Rap of the mutation.

Lifestyle affects T2DM and having a sedentary life is a known risk factor (28), while exercise can prevent impaired glucose tolerance from progressing into T2DM by $\sim 60 \%(29,30)$. Although the present study did not identify an association between exercise and rs3773958 due to missing data, elevated risks were noted for IGR in GT and GT + GG subgenotypes compared to the TT genotype in non-drinking and non-smoking subgroups. As rs3773958 did not interact with drinking and smoking and also since the same result was obtained in the non-overweight subgroup, the GT and GT + GG subgenotypes may be used in predicting whether individuals with these genotypes will develop IGR. While a 24-year cohort study in a South Carolina community showed that weekly drinking was associated with T2DM (30), another study showed that light-to-moderate alcohol consumption can improve lipid-related indices in T2DM (31). The effect of smoking on T2DM is as controversial as drinking $(32,33)$. However, smoking and drinking can further increase the blood sugar concentration (34). These studies support the complex associations between drinking, smoking and T2DM. However, since the present study did not indicate that there were any significant differences in smoking or drinking between the case and control groups, more studies are required.

The present study has several strengths. First, a relatively large Chinese Han population was used, thereby minimizing the possible impact of ethnicity on the results and providing sufficient power to discover SNPs. Second, to the best of our knowledge, this is the first study to investigate the association between SNPs in the IL-1Rap gene and IGR. However, the study was complicated by a few limitations. Firstly, the relevance of $\mathrm{HbA}_{1 \mathrm{c}}$ data to determine the exact status of glucose metabolism pathways was not investigated, thus potentially introducing selection bias. Additionally, the mRNA or protein levels of IL-1Rap, and the affinity of the IL-1- $\beta /$ IL-1R or 
IL-33/ST2 complex for IL-1Rap were not analyzed and these should be studied in the future in order to more fully elucidate the roles of these proteins in the pathogenesis of IGR. Finally, due to the cross-sectional nature of the study, a causal association cannot be concluded.

In conclusion, an association between rs3773958, an SNP in the IL-1Rap gene and IGR has been demonstrated in the Chinese Han population.

\section{Acknowledgements}

The authors would like to thank all the individuals who participated in the present study.

\section{References}

1. Xu Y, Wang L, He J, Bi Y, et al: Prevalence and control of diabetes in Chinese adults. JAMA 310: 948-959, 2013.

2. Tack CJ, Stienstra R, Joosten LA and Netea MG: Inflammation links excess fat to insulin resistance: The role of the interleukin-1 family. Immunol Rev 249: 239-252, 2012.

3. Oh YS, Lee YJ, Park EY and Jun HS: Interleukin-6 treatment induces beta-cell apoptosis via STAT-3-mediated nitric oxide production. Diabetes Metab Res Rev 27: 813-819, 2011.

4. Kahn BB: Type 2 diabetes: When insulin secretion fails to compensate for insulin resistance. Cell 92: 593-596, 1998.

5. Banerjee M and Saxena M: Interleukin-1 (IL-1) family of cytokines: Role in type 2 diabetes. Clin Chim Acta 413: 1163-1170, 2012

6. Pradhan AD, Manson JE, Rifai N, Buring JE and Ridker PM: C-reactive protein, interleukin 6 and risk of developing type 2 diabetes mellitus. JAMA 286: 327-334, 2001.

7. Spranger J, Kroke A, Möhlig M, Hoffmann K, Bergmann MM, Ristow M, Boeing $\mathrm{H}$ and Pfeiffer AF: Inflammatory cytokines and the risk to develop type 2 diabetes: Results of the prospective population-based European Prospective Investigation into Cancer and Nutrition (EPIC)-Potsdam Study. Diabetes 52: 812-817, 2003

8. Miller AM, Asquith DL, Hueber AJ, Anderson LA, Holmes WM, McKenzie AN, Xu D, Sattar N, McInnes IB and Liew FY: Interleukin-33 induces protective effects in adipose tissue inflammation during obesity in mice. Circ Res 107: 650-658, 2010.

9. Coglianese EE, Larson MG, Vasan RS, Ho JE, Ghorbani A, McCabe EL, Cheng S, Fradley MG, Kretschman D, Gao W, et al: Distribution and clinical correlates of the interleukin receptor family member soluble ST2 in the Framingham Heart Study. Clin Chem 58: 1673-1681, 2012.

10. Miller AM, Purves D, McConnachie A, Asquith DL, Batty GD, Burns H, Cavanagh J, Ford I, McLean JS, Packard CJ, et al: Soluble ST2 associates with diabetes but not established cardiovascular risk factors: A new inflammatory pathway of relevance to diabetes? PLoS One 7: e47830, 2012.

11. Marques-Vidal P, Schmid R, Bochud M, Bastardot F, von Känel R, Paccaud F, Glaus J, Preisig M, Waeber G and Vollenweider P: Adipocytokines, hepatic and inflammatory biomarkers and incidence of type 2 diabetes. The CoLaus study. PLoS One 7: e51768, 2012.

12. Ali S, Huber M, Kollewe C, Bischoff SC, Falk W and Martin MU: IL-1 receptor accessory protein is essential for IL-33-induced activation of T lymphocytes and mast cells. Proc Natl Acad Sci USA 104: 18660-18665, 2007.

13. Wesche H, Korherr C, Kracht M, Falk W, Resch K and Martin MU: The interleukin-1 receptor accessory protein (IL-1RAcP) is essential for IL-1-induced activation of interleukin-1 receptor-associated kinase (IRAK) and stress-activated protein kinases (SAP kinases). J Biol Chem 272: 7727-7731, 1997.

14. Wang Z, Zheng C, Tan YY, Li YJ, Yang L, Huang G, Lin J and Zhou ZG: Gene expression changes in patients with fulminant type 1 diabetes. Chin Med J (Engl) 124: 3613-3617, 2011.

15. He MA, Zhang X, Wang J, Cheng L, Zhou L, Zeng H, Wang F, Chen Y, Xu Z, Wei Q, et al: Genetic variation in heat shock protein 60 gene and coronary heart disease in China: tagging-SNP haplotype analysis in a case-control study. Cell Stress Chaperones 13: 231-238, 2008.
16. Liew FY, Pitman NI and McInnes IB: Disease-associated functions of IL-33: The new kid in the IL-1 family. Nat Rev Immunol 10: 103-110, 2010.

17. McLaren JE, Michael DR, Salter RC, Ashlin TG, Calder CJ, Miller AM, Liew FY and Ramji DP: IL-33 reduces macrophage foam cell formation. J Immunol 185: 1222-1229, 2010.

18. Miller AM, Xu D, Asquith DL, Denby L, Li Y, Sattar N, Baker AH, McInnes IB and Liew FY: IL-33 reduces the development of atherosclerosis. J Exp Med 205: 339-346, 2008.

19. Wood IS, Wang B and Trayhurn P: IL-33, a recently identified interleukin-1 gene family member, is expressed in human adipocytes. Biochem Biophys Res Commun 384: 105-109, 2009.

20. Zeyda M, Wernly B, Demyanets S, Kaun C, Hämmerle M, Hantusch B, Schranz M, Neuhofer A, Itariu BK, Keck M, et al: Severe obesity increases adipose tissue expression of interleukin-33 and its receptor ST2, both predominantly detectable in endothelial cells of human adipose tissue. Int J Obes 37: 658-665, 2013.

21. Zdravkovic N, Pavlovic S, Zdravkovic V, Pejnovic N, Arsenijevic N and Lukic ML: ST2 gene-deletion reveals a role of Foxp3 ${ }^{+}$regulatory $\mathrm{T}$ cells in diabetes modulation in BALB/c mice. Transl Res 161: 118-129, 2013.

22. Zdravkovic N, Shahin A, Arsenijevic N, Lukic ML and Mensah-Brown EP: Regulatory T cells and ST2 signaling control diabetes induction with multiple low doses of streptozotocin. Mol Immunol 47: 28-36, 2009.

23. Ehses JA, Lacraz G, Giroix MH, Schmidlin F, Coulaud J, Kassis N, Irminger JC, Kergoat M, Portha B, Homo-Delarche F, et al: IL-1 antagonism reduces hyperglycemia and tissue inflammation in the type 2 diabetic GK rat. Proc Natl Acad Sci USA 106: 13998-14003, 2009.

24. Lucas R, Parikh SJ, Sridhar S, Guo DH, Bhagatwala J, Dong Y, Caldwell R, Mellor A, Caldwell W, Zhu H, et al: Cytokine profiling of young overweight and obese female African American adults with prediabetes. Cytokine 64: 310-315, 2013.

25. Palmer G, Lipsky BP, Smithgall MD, Meininger D, Siu S, Talabot-Ayer D, Gabay C and Smith DE: The IL-1 receptor accessory protein (AcP) is required for IL-33 signaling and soluble AcP enhances the ability of soluble ST2 to inhibit IL-33. Cytokine 42: 358-364, 2008.

26. Smeets RL, van de Loo FA, Joosten LA, Arntz OJ, Bennink MB, Loesberg WA, Dmitriev IP, Curiel DT, Martin MU and van den Berg WB: Effectiveness of the soluble form of the interleukin-1 receptor accessory protein as an inhibitor of interleukin-1 in collagen-induced arthritis. Arthritis Rheum 48: 2949-2958, 2003

27. Smith DE, Hanna R, Della Friend, Moore H, Chen H, Farese AM, MacVittie TJ, Virca GD and Sims JE: The soluble form of IL-1 receptor accessory protein enhances the ability of soluble type II IL-1 receptor to inhibit IL-1 action. Immunity 18: 87-96, 2003.

28. Shaw JE and Chisholm DJ: 1: Epidemiology and prevention of type 2 diabetes and the metabolic syndrome. Med J Aust 179: 379-383, 2003.

29. Eriksson J, Lindström $\mathbf{J}$ and Tuomilehto J: Potential for the prevention of type 2 diabetes. Br Med Bull 60: 183-199, 2001.

30. McEvoy LK, Kritz-Silverstein D, Barrett-Connor E, Bergstrom J and Laughlin GA: Changes in alcohol intake and their relationship with health status over a 24-year follow-up period in community-dwelling older adults. J Am Geriatr Soc 61: 1303-1308, 2013.

31. Shimomura T and Wakabayashi I: Inverse associations between light-to-moderate alcohol intake and lipid-related indices in patients with diabetes. Cardiovasc Diabetol 12: 104, 2013.

32. Tentolouris N, Andrianakos A, Karanikolas G, Karamitsos D, Trontzas P, Krachtis P, Christoyannis F, Tavaniotou E, Nikolia Z, Kaskani E, et al: Type 2 diabetes mellitus is associated with obesity, smoking and low socioeconomic status in large and representative samples of rural, urban and suburban adult Greek populations. Hormones (Athens) 11: 458-467, 2012.

33. Kengne AP, Nakamura K, Barzi F, Lam TH, Huxley R, Gu D, Patel A, Kim HC and Woodward M; Asia Pacific Cohort Study Collaboration: Smoking, diabetes and cardiovascular diseases in men in the Asia Pacific region. J Diabetes 1: 173-181, 2009.

34. Pathak R and Pathak A: Study of life style habits on risk of type 2 diabetes. Int J Appl Basic Med Res 2: 92-96, 2012. 